\title{
Ependyma and Remnants of the Central Canal of the Spinal Cord
}

National Cancer Institute

\section{Source}

National Cancer Institute. Ependyma and Remnants of the Central Canal of the Spinal

Cord. NCI Thesaurus. Code C41623.

Structures that have evolved from embryonic development of the neural tube. The ependyma is a specialised epithelium lining the ventricles and central canal of the brain and spinal cord. The remnants of the central canal of the spinal cord represent modified ependyma left from embryonic development of the neural tube 